\title{
El cine personal y político de Travis Wilkerson
}

La Cátedra Ingmar Bergman en cine y teatro es una iniciativa de la Universidad Nacional Autónoma de México, a través de la Coordinación de Difusión Cultural, con el fin de contar con un espacio de reflexión y formación académica que fortalezca y amplíe la cultura cinematográfica y teatral entre los universitarios y la sociedad. Desde 2010, la Cátedra promueve ocasiones especiales de reflexión y debate sobre el papel del teatro y la cultura cinematográfica en la vida contemporánea, a través del diálogo con destacados artistas e intelectuales en ambas disciplinas.

Desde su primera edición, la Cátedra Bergman ha sido cómplice del Festival Internacional de Cine de la UnAm (FICUNAM) en la búsqueda de un espacio para la reflexión académica con invitados que han enriquecido con sus obras el mundo del cine y del arte en general y que cada año asisten a este festival.

Si algo distingue al FICUNAM de otros festivales de cine es su programación, enfocada en el trabajo de jóvenes talentos y creadores consagrados de difícil acceso en México. Para la Cátedra Bergman es muy importante contar con este espacio de colaboración.

En el marco de la octava edición del FICUNAM, que se realizó del 28 de febrero al 6 de marzo de 2018, la Cátedra Bergman organizó una clase magistral con el cineasta estadounidense Travis Wilkerson, considerado por algunos como el creador del Tercer Cine. Además de esta clase magistral, el FICUNAM dedicó una retrospectiva a su trabajo fílmico.

El jueves 1 de marzo, en el Auditorio del Museo Universitario Arte Contemporáneo, Wilkerson compartió con el público su historia desde la intimidad: cómo llegó al cine de manera inesperada y por qué el enfoque tan personal y político de su obra cinematográfica. 
Hijo de una mujer que creció en el sur de Estados Unidos durante las leyes de segregación de Jim Crow, y de un piloto de helicóptero condecorado en la Guerra de Vietnam, creció odiando el racismo y la guerra. Este odio, como una especie de religión, está también siempre presente en su trabajo.

Llegó al cine de manera indirecta, después de conocer al cineasta cubano Santiago Álvarez, mientras estudiaba agricultura orgánica en La Habana. Su primer largometraje, titulado Accelerated Under Development in the Idiom of Santiago Álvarez (1999), es una aclaración de principios: se trata de un retrato del cineasta radical cubano. Para Travis, la lección más importante que le dejó su cercanía con Álvarez es la noción de que, contrario a lo que la mayoría de los cineastas piensan, la idea es más importante que los recursos: "Santiago Álvarez jamás dejó que la falta de recursos interfiriera con su habilidad para hacer una película bajo ninguna circunstancia". Y con esta noción radical y reveladora, Travis Wilkerson jamás ha permitido que la falta de recursos interfiera con su práctica cinematográfica. Así, también encontramos en su obra el uso de material de archivo, de su propia voz, de su propia presencia física, buscando el equilibrio entre un compromiso social profundo y una riqueza estética: "El centro de mi trabajo tiene que ver con la excavación en la historia, en el paisaje, en los medios, en la familia y en los aspectos profundamente personales".

Para Wilkerson, existe una incapacidad casi patológica del poder político y las fuerzas más reaccionarias de los Estados Unidos para la introspección. Por eso le interesa cada vez más la idea de ver hacia adentro de una forma profunda y humilde, porque "ver hacia adentro es también ver hacia fuera". Ver hacia adentro de su propia familia. En su más reciente trabajo Did You Wonder Who Fired the Gun? (2017), documental que explora el asesinato de un hombre negro en Alabama en los años cuarenta, cometido por su bisabuelo S. E. Branch; Wilkerson buscaba hablar clara y honestamente acerca de la historia de su familia y su interconexión con los peores impulsos de la sociedad estadounidense. Porque lejos de ser una forma de narcisismo, es la única manera de movernos hacia una dirección distinta.

Durante más de dos décadas, Travis Wilkerson ha trabajado como artista en los medios independientes, moviéndose entre los diferentes 
géneros a partir de aproximaciones no tradicionales, siempre desde una perspectiva crítica. Sus temas van desde el legado del cine radical, el sindicalismo en el oeste de Estados Unidos, el racismo de las leyes de segregación de Jim Crow y sus resultados, hasta las guerras en el sureste asiático. Es escritor, actor, director, productor, editor, fotógrafo, diseñador y voz en off de sus películas; esto, con la intención de trabajar de un modo liberador y autosuficiente.

"En el centro de mi trabajo está la búsqueda de la unión entre la elocuencia estética y el compromiso social, producido con una modestia absoluta en términos de los recursos materiales."

Esta clase magistral está disponible para su consulta en el canal de YouTube de la Cátedra Ingmar Bergman.

Mariana GutiérRez Noriega 